\title{
Work Hardening Characteristics of the Basal Slip of Magnesium Single Crystals
}

\author{
By Hideo Yoshinaga* and Ryo Horiuchi*
}

\begin{abstract}
The work hardening characteristics of the basal slip of magnesium have been investigated by tension test at elevated temperatures, from room temperature to $300^{\circ} \mathrm{C}$, using crystals of various orientations. The resolved shear stress shear strain curves obtained typically consist of two stages. The first is the well known easy glide region, and the second is a rapid hardening region which corresponds to the so-called stage II of f. c. c. metals, but in these curves the region corresponding to the stage III of f.c.c. metals is not observed. Stage II of magnesium basal slip decreases with increasing temperature, and disappears above $200^{\circ} \mathrm{C}$. From the results of tension tests and metallographical examinations, it is concluded that the hardening mechanism of basal slip in stage II is much different from that of the octahedral slip in f.c.c. metals, and it depends on the $\{11 \overline{2} 0\}$ kink bands locked by the formation of $\{10 \overline{1} 2\}$ twins.
\end{abstract}

(Received Decémber 5, 1962)

\section{Introduction}

The work hardening behavior of single crystals of f.c.c. metals has been investigated in detail by many investigators, while basal slip of h.c.p. metals has not been reported in great detail, except their easy glide regions.

In the wide orientation range of single crystals, h.c.p. metals such as magnesium, zinc and cadmium deform by a single deformation mechanism (basal slip) over a wide plastic range, as a result their easy glide regions (stage I) are considerably wide compared with of f.c.c. metals. However, following stage I, rapid hardening like the stage II of f.c.c. metals also occurs in the basal slip deformation when the test temperature is not very high $^{(1) \sim(8)}$.

In the case of these basal slip deformations, LomerCottrell type sessile dislocations would not be produced. Then it may not be possible to interpret the rapid hardening of the basal slip by the same mechanism as that of octahedral slip in f.c.c. metals. In this paper, this problem will be discussed from the results of tension tests and metallographic observations.

\section{Experimental Procedure}

\section{Specimen}

The tensile specimens shown in Fig. 1 were produced from extruded bars of high purity magnesium $(>99.99$ $\%$ ). These polycrystalline specimens were packed with graphite powder in a stainless steel pipe and were made into single crystals by the Bridgman method in an argon atmosphere. The orientations were determined

* Aeronautical Research Institute, University of Tokyo, Komaba, Meguro-ku, Tokyo.

(1) W. Fahrenhorst und E. Schmid: Z. Phys., 64 (1930), 845.

(2) J. Gilman : Trans. AIME, 194 (1952), 875.

(3) K.Lücke, G. Masing und K. Schröder : Z. Metallk., 46 (1955), 792 .

(4) W. Boas und E. Schmid: Z. Phys., 54 (1929), 16.

(5) W. Boas und E. Schmid: Z. Phys., 61 (1930), 767.

(6) E. N. da C. Andrade and R. Roscoe : Proc. Phys. Soc., 49 (1937), 152.

(7) E. Schmid: Z. Elektrochem., 37 (1931), 447.

( 8 ) H.Asada and H. Yoshinaga : J. Japan Inst. Metals, 23 (1959), 649. (In Japanese) by the transmission Laue method. After electrolytic polishing, specimens were subjected to tension tests and metallographic examinations.

\section{Tensile test}

The tensile test machine used was a horizontal type with a heating furnace designed especially for this experiment. A load cell of wire electric resistance strain gauge type was used to measure the load. The strain power produced in this load cell was automatically recorded by a autobalance type strain meter.

The measuring error in this apparatus was within 1 per cent of the load. Tensile speed was maintained at $1 \mathrm{~mm} / \mathrm{min}$., and the running speed of the recording chart, $600 \mathrm{~mm} / \mathrm{min}$. The elongation of a specimen was determined from the ratio of these two speeds. The temperature was controlled within $\pm 2{ }^{\circ} \mathrm{C}$ automatically by a Prosser type regulator.

\section{Experimental Results}

\section{Orientation dependence}

In order to investigate the orientation dependence of the work hardening behavior, crystals of various orientations were tested at room temperature. Resulting curves are shown in Fig. 1. Metallographic observations showed that these crystals deformed by basal slip. From these curves, it can be seen that the work hardening behavior does not depend so much on the crystal orientation under the present test conditions, except 0-17 specimen which fractured at an early stage of deformation, because its orientation of small $\chi_{b}$ (the angle between basal plane and tension axis) was unfavourable for basal slip, but favourable for pyramidal fracture $^{(8)}$.

\section{Temperature dependence}

In order to investigate the temperature dependence of the work hardening behaviour, crystals of nearly the same orientation were tested at room temperaturer, $100^{\circ} \mathrm{C}, 200^{\circ} \mathrm{C}$ and $300^{\circ} \mathrm{C}$. Resulting curves are shown in Fig. 2. As the temperature increases, the easy glide region becomes wider and stage II is reduced, and 
finally disappears above $200^{\circ} \mathrm{C}$.

\section{Metallographic observation}

In the metallographic observations of the deformation process, heterogeneous deformation as shown in Photo.

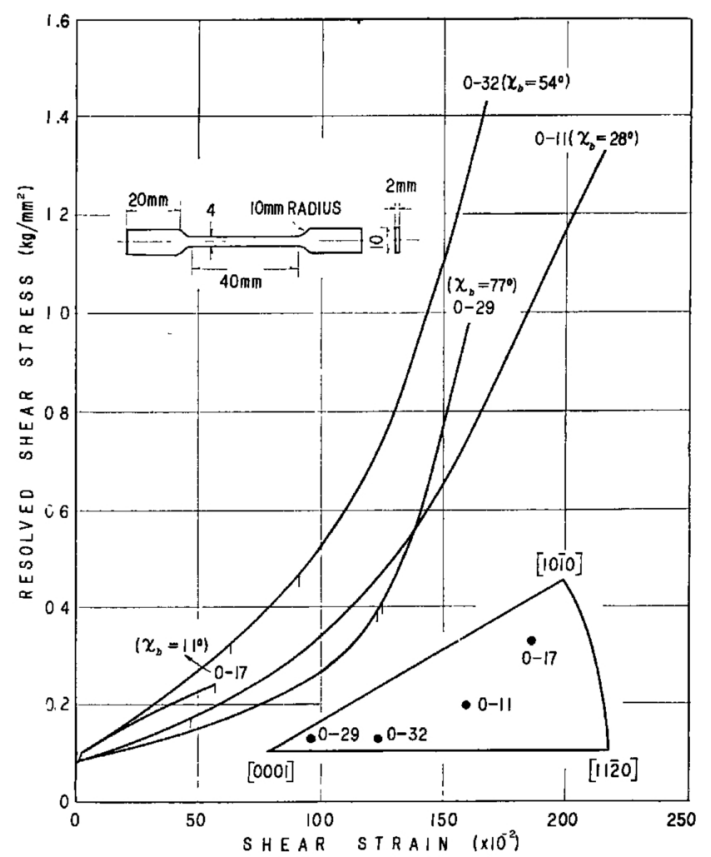

Fig. 1 Resolved shear stress-shear strain curves for basal slip at room temperature.

1 was sometimes observed at an early stage of deformation (in many cases, deformation started in the middle part of the specimen). This heterogeneous deformation sometimes caused a yield point phenomenonlike behavior in the stress-strain curves, as shown in Fig. $2\left(0-23\right.$ at $200^{\circ} \mathrm{C}$ and $\mathrm{MO}-1$ at $\left.300^{\circ} \mathrm{C}\right)$, probably
As the deformation increased further, $\{11 \overline{2} 0\}$ kink bands with many $\{10 \overline{1} 2\}$ twins ${ }^{(9)}$ Photo. 3 and Fig. 3 occurred at the beginning of the rapid hardening in stage II. $\chi_{b}$ of this specimen was $77^{\circ}$ and six kinds of $\{10 \overline{1} 2\}$ twins were observed, because the difference of

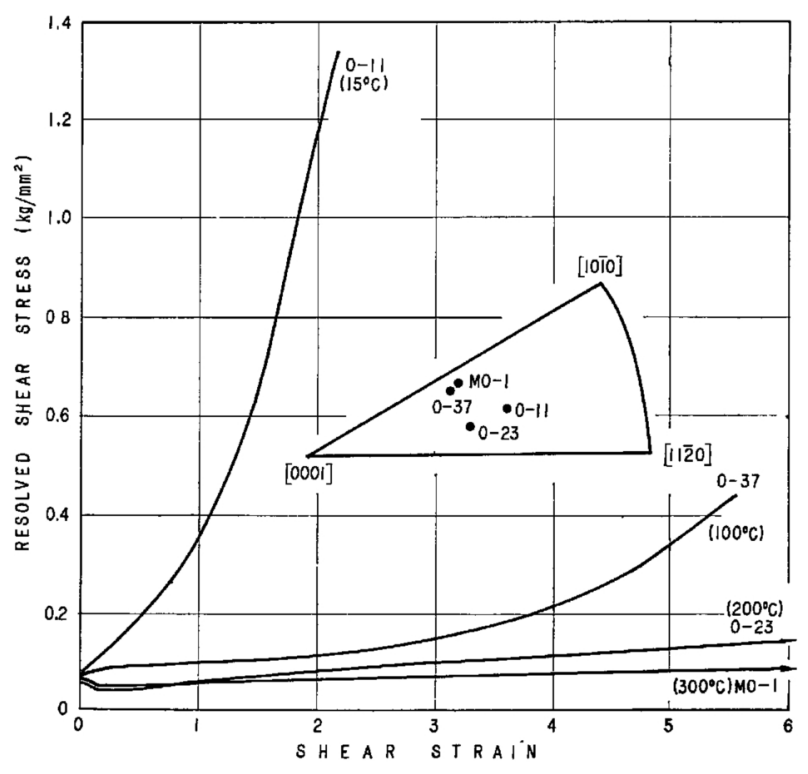

Fig. 2 Resolved shear stress-shear strain curves for basal slip at various temperatures.

the orientation factor was within 10 per cent between these six $\{10 \overline{1} 2\}$ twinning systems in this specimen.

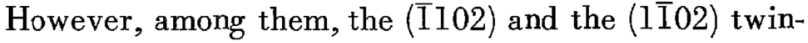
ning systems had the largest orientation factor, and twin forms of these kinds occurred most frequently, as shown in Fig. 3. These kink bands did not migrate during further deformation, but their number increased. Then many noncrystallographic bendings

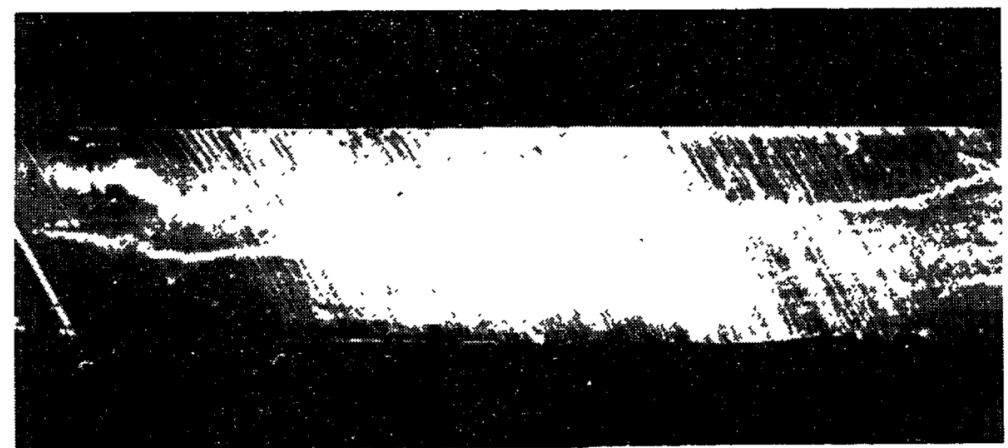

Photo. 1 Heterogeneous deformation.

because the work hardening rate was very small at this deformation stage especially at high temperatures and the shear stress-shear strain curves shown in Fig. 2 were determined by calculation, assuming uniform deformation over the entire gauge length of the specimen. In these cases, $\{11 \overline{2} 0\}$ type $\operatorname{kinking}^{(9)}$ as shown in Photo. 2 was sometimes observed along the boundary of the heterogeneous deformation. But this type kinking showed little effect on the work hardening.

These kink planes migrated to the gripped portions of the specimen as the deformation increased, and then the strain of the specimen became more uniform.

(9) E. C. Burke and W. R. Hibbard: Trans. AIME, 194 (1952), 295.
Photo. 4 were formed, and finally the crystals were heavily twisted as shown in Photo. 5 (a). Sometimes a jerky flow was observed in stage II as shown in Fig. 1 , and at that time a slight twin cry could be heard. This jerky flow may correspond to the formation of the kink band with $\{10 \overline{1} 2\}$ twins. As the temperature increased, these kink bands with $\{10 \overline{1} 2\}$ twins were formed less frequently and the surface of the heavily deformed crystals became smooth as shown in Photo. 5 (b).

These two kinds of kinking, Photo. 2 type and Photo. 3 type, were always along a $\{11 \overline{2} 0\}$ plane normal to the active glide direction of the basal slip, as reported by Burke and Hibbard ${ }^{(9)}$. 


\section{Discussion}

The work hardening characteristics of magnesium basal slip compared with those of octahedral slip of f.c.c. metals may be summarized as follows: sium, this region is very wide and becomes much wider as the temperature increases, as shown in Table 1.

(2) Stage II (rapid hardening region); The work hardening rate in this stage of f.c.c. metals is about $1 / 300$ of the shear modulus $\mu$ and is independent of

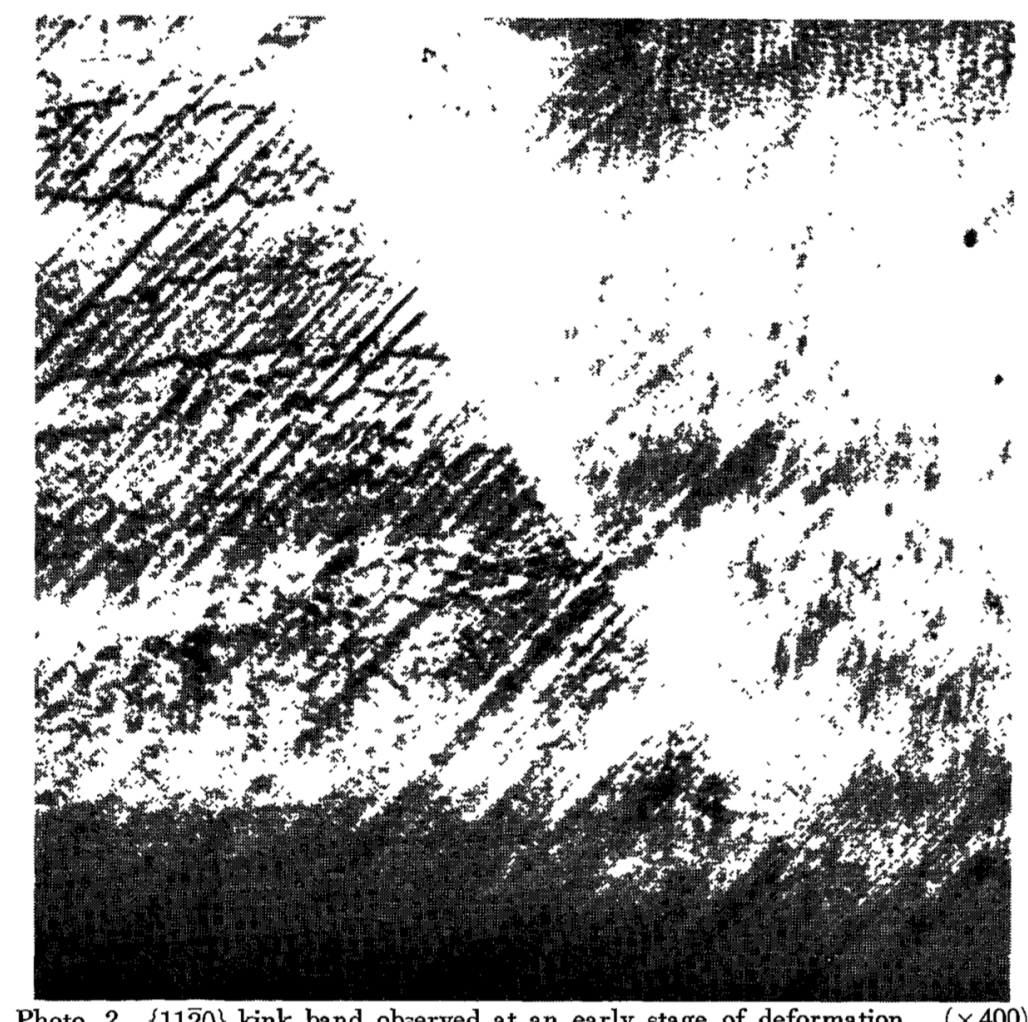

Photo. $2\{11 \overline{2} 0\}$ kink band observed at an early stage of deformation. $(\times 400)$

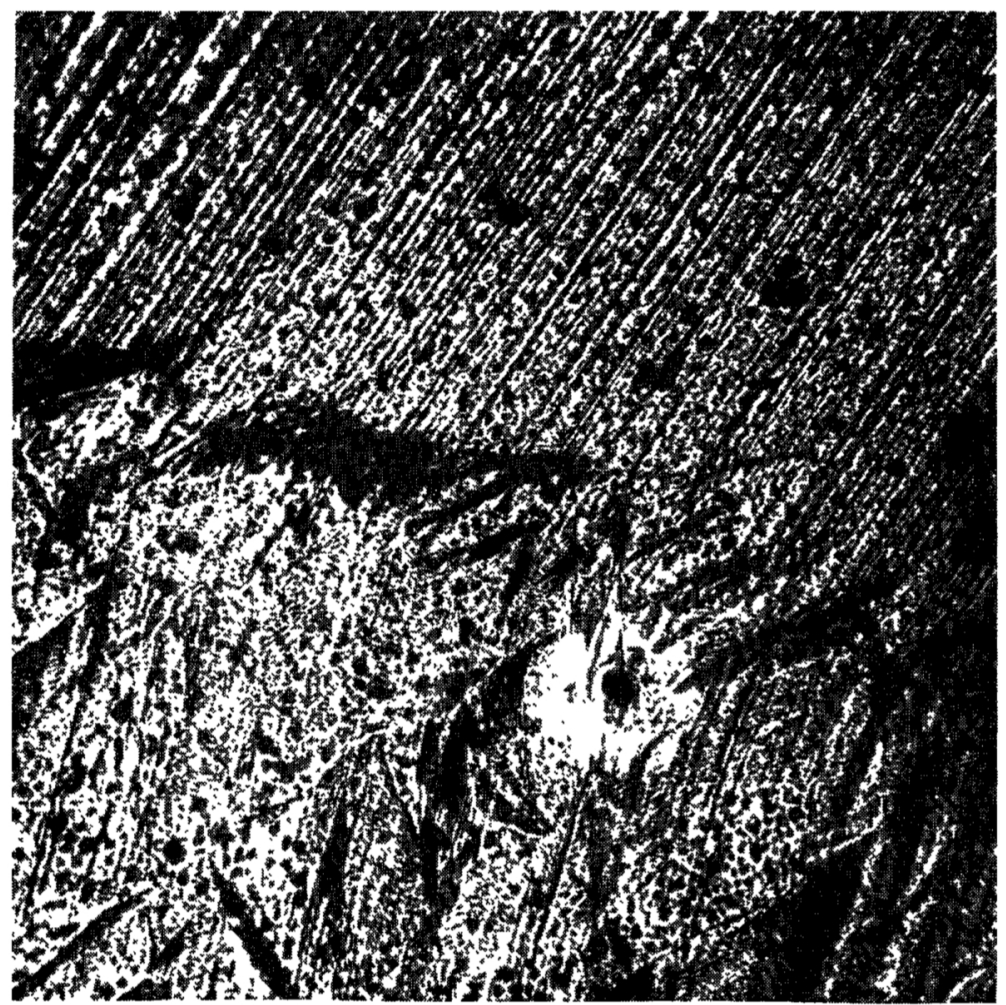

Photo. $3\{11 \overline{2} 0\}$ kink band with many $\{10 \overline{1} 2\}_{-}^{\prime}$ wins observed in stage II. $(\times 1000)$

(1) Stage I (easy glide region); In the case of f.c.c. metals, this region which is usually very narrow, decreases as the temperature increases and finally it disappears ${ }^{(10)}$, while in the case of basal slip in magne- test temperature (11) (but at higher temperatures this

(10) E. N. da C. Andrade and D. A. Aboav : Proc. Roy. Soc., A 240 (1957), 304.

(11) D. Kuhlmann-Wilsdorf: Z. Metallk., 53 (1962), 324. 
stage is blurred and stage III starts at an early stage of deformation), while stage II of the basal slip in magnesium is remarkably dependent on temperature (1 $\sim 2 \mathrm{~kg} / \mathrm{mm}^{2}$ at room temperature, $0.16 \mathrm{~kg} / \mathrm{mm}^{2}$ at $100^{\circ} \mathrm{C}$, and above $200^{\circ} \mathrm{C}$ this stage is not observed).
These differences might show that the work hardening mechanisms would be different between basal slip and octahedral slip. In the case of single basal slip deformation, Lomer-Cottrell type sessile dislocations would not be formed (this is the widely accepted reason

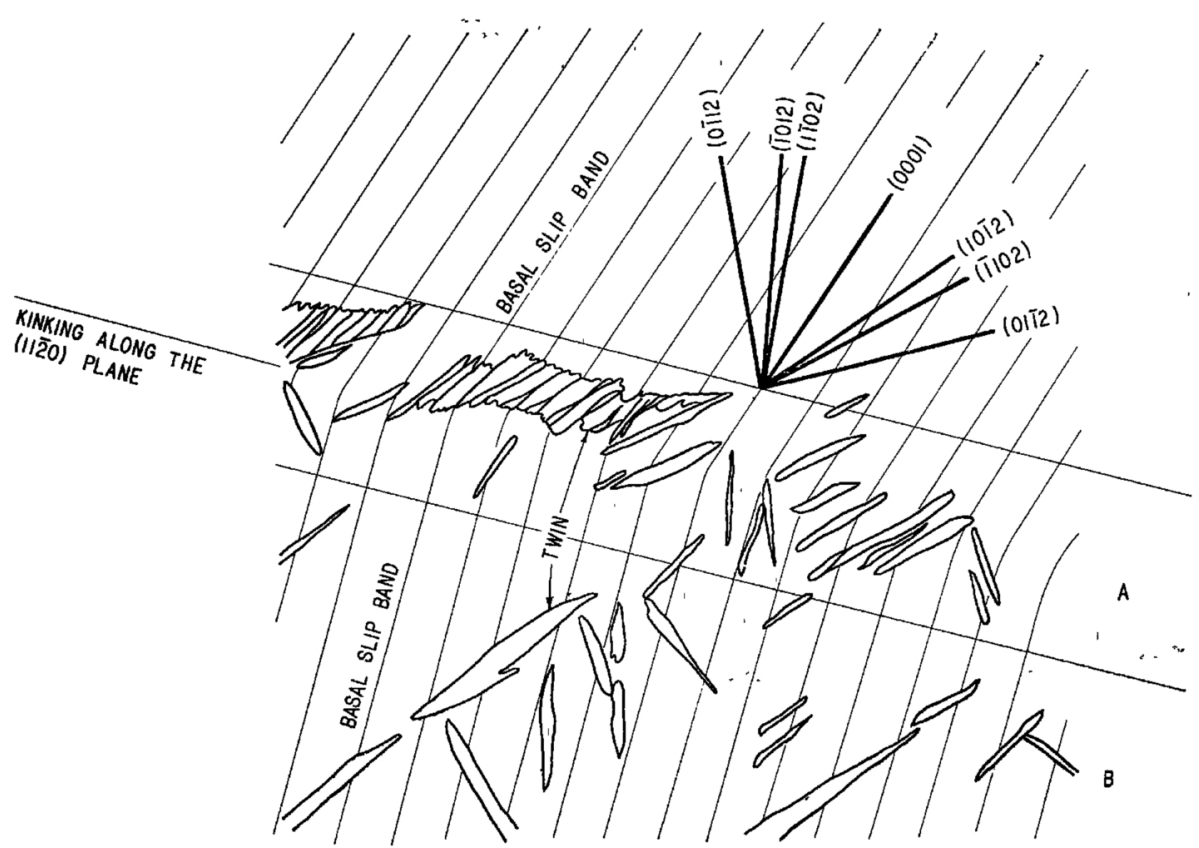

Fig 3 Illustration for Photo. 3. Many fine twins along kinking in the A region are considered to have been produced probably to accommodate the dislocation pile up, while the twins in $B$ region, probably to accommodate the macroscopic bending of the specimen.

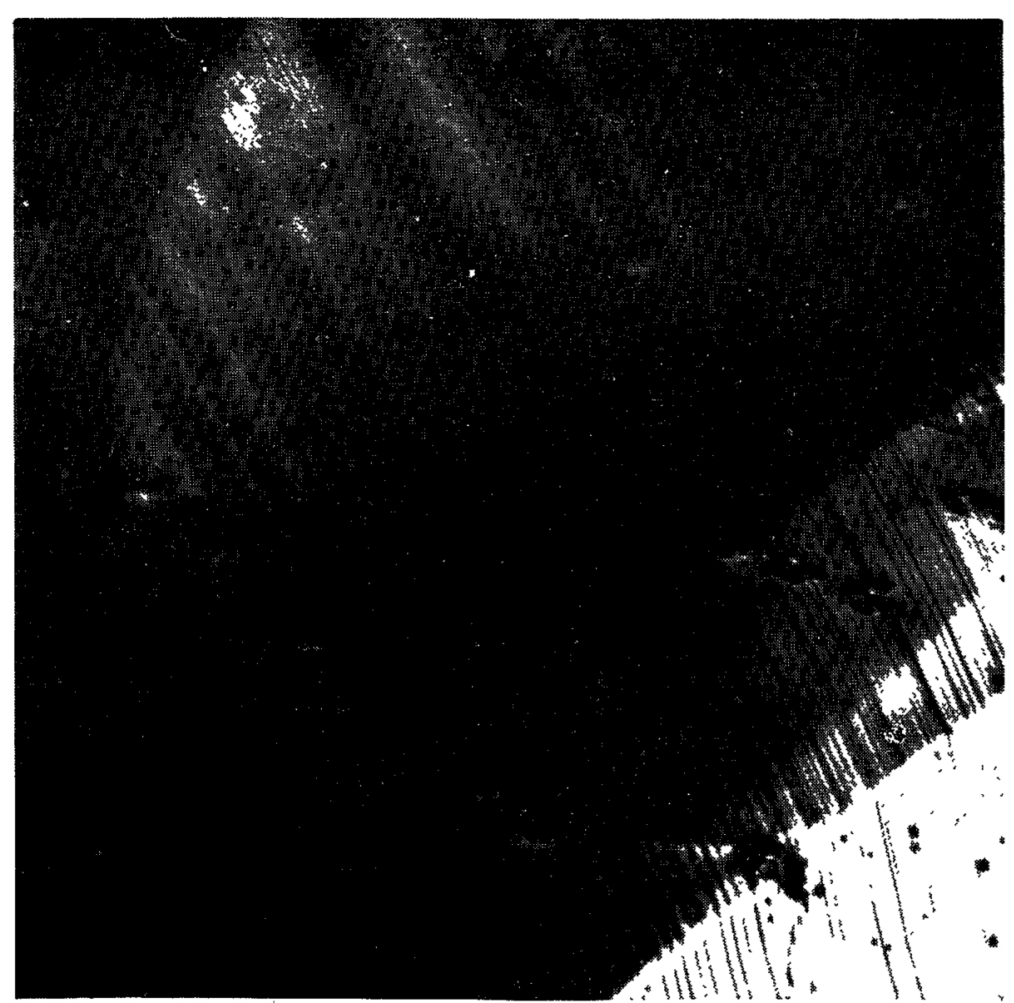

Photo. 4 Noncrystallographic bending observed after fracture. $(\times 500)$

(3) Stage III (parabolic hardening region following stage II); This work hardening stage, which is usually observed in f.c.c. metals except at considerably low temperatures, is not found in the case of magnesium basal slip. (However, this stage is reported to exist in $\operatorname{zinc}^{(3)}$ ). why the easy glide region is very wide in the case of such basal slip), as already mentioned. Then the work hardening may be due to the interaction of the parallel dislocations of opposite signs ${ }^{(12)}$, intersection of dislocations etc. (13) 
From the measurements of the flow stress by Conrad et al. (14)(15) and of the temperature dependence of the critical resolved shear stress ${ }^{(16)}$, it seems that the flow stress in the easy glide region is determined by the back stress from the dislocations nearly parallel to the
The interaction of the parallel dislocations of opposite signs on the glide planes apart in such a large distance yields only a small obstructing stress of the order of $10^{-6}$ to $10^{-5} \mu$ to the gliding dislocations ${ }^{(17)}$. Therefore these obstacles can be easily overcome. Then they
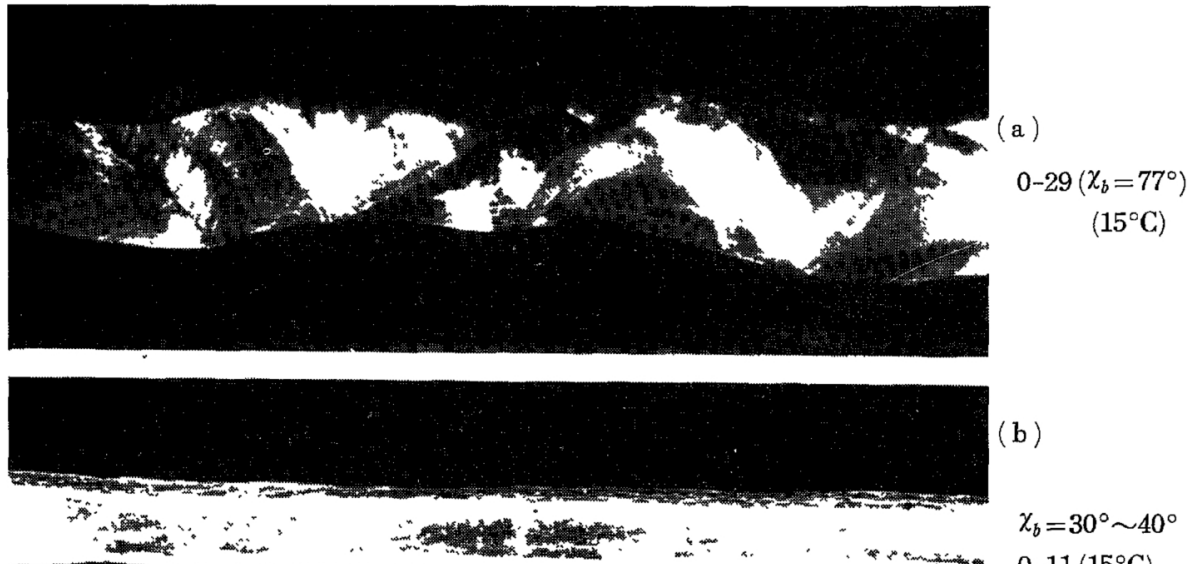

(b)

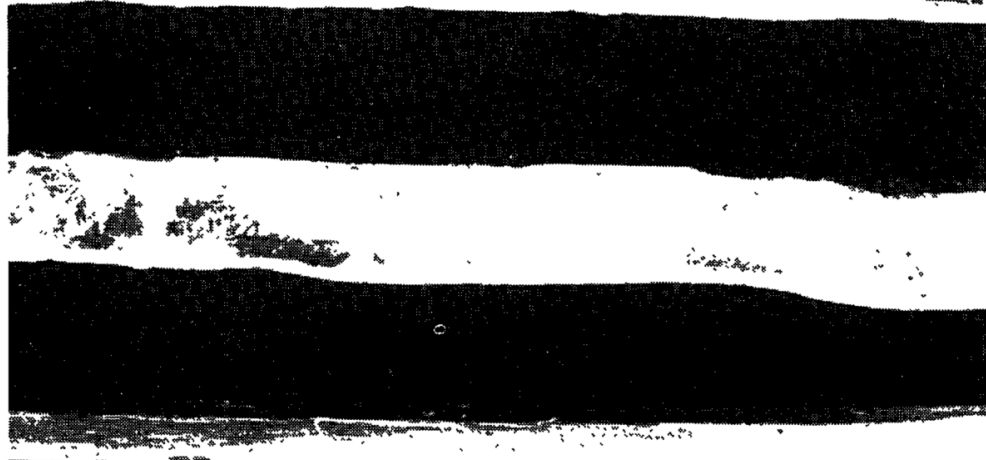

$\chi_{b}=30^{\circ} \sim 40^{\circ}$

$0-11\left(15^{\circ} \mathrm{C}\right)$

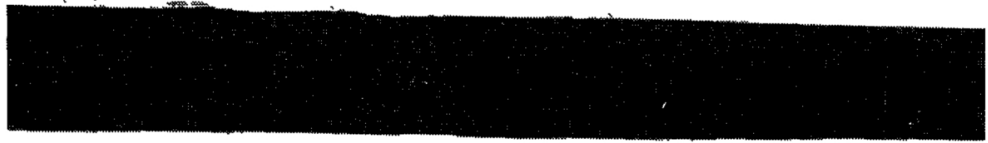

$0-23\left(200^{\circ} \mathrm{C}\right)$

$0-37\left(100^{\circ} \mathrm{C}\right)$

M $0-1\left(300^{\circ} \mathrm{C}\right)$

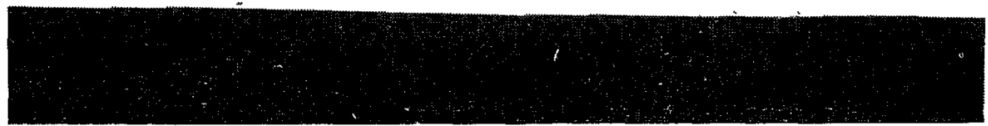

Photo. 5 (a) Heavily twisied crystal, after fracture.

(b) Heavily deformed crystals.

$0-11$; afier $95 \%$ elongation (fractured)

$0-37$; after $320 \%$ elongation (fractured)

0-23 and M 0-1; after $360 \%$ elongation (not fractured)

As the iest temperaitre increases, the surface of the specimen becomes smoother.

gliding ones and forest dislocations have trivial effects on the flow stress when magnesium crystals are extended above room temperature and in such a low strain rate as the present investigation, and also it seems that the slight hardening observed in the easy glide region is mainly due to the increase of these dislocations nearly paralle! to the gliding ones.

The mean spacing. of basal slip bands observed at the early stage of easy glide region is $10^{-3}$ to $10^{-4} \mathrm{~cm}$.

(13) A. Hujita and T. Suzuki : Teni-ron no kinzoku eno oyo (Applications of Dislocation Theory to Metals), (1957), 128, the Japan Institute of Metals. In Japanese.

(14) H. Conrad, R. Armstrong, H. Wiedersich and G. Schoeck: Phil. Mag., 6 (1961), 177.

(15) H. Conrad, L. Hays, G. Schoeck and H. Wiedersich : Acta Met., 9 (1961), 367.

(16) W. F. Sheely, E. D. Levine and R. R. Nash: Trans. AIME $215(1959), 693$.
Table 1 The work hardening rate and the width of the easy glide region.

\begin{tabular}{r|c|c}
\hline $\begin{array}{c}\text { Test temp. } \\
\left({ }^{\circ} \mathrm{C}\right)\end{array}$ & $\begin{array}{c}\text { Work hardening } \\
\text { raie }\left(\mathrm{g} / \mathrm{mm}^{2}\right)\end{array}$ & $\begin{array}{c}\text { Width } \\
\text { (shear strain) }\end{array}$ \\
\hline 15 & $130 \sim 230$ & 1 \\
100 & 15 & 3 \\
200 & 15 & $>6$ \\
300 & 8 & $>6$ \\
\hline
\end{tabular}

cannot contribute to the work hardening very much. (The $\{11 \overline{2} 0\}$ kink bands which were sometimes formed at the early stage of deformation probably by the bending stress due to heterogeneous deformation, was

(17) A. H. Cottrell : Dislocation and Plastic Flow in Crystals, (1953), 153, Oxford.

(18) J. Washburn and E. R. Parker: J. Metals, 4(1952), 1076. 
found to migrate under low applied stress of about $100 \mathrm{~g} / \mathrm{mm}^{2}$. Accordingly these kink bands have also little effect on the work hardening. These low angle symmetrical tilt boundaries composed of parallel edge dislocations are known to be highly mobile(18).) However, the mean spacing of basal slip bands observed at the later stage of easy glide decreases to about $10^{-6} \mathrm{~cm}$. Then the obstructing stress yielded by the interaction of the parallel dislocations of opposite signs may increase to about $10^{-3} \mu \approx 2 \mathrm{~kg} / \mathrm{mm}^{2}$. These obstacles may not afford so large a pile up of gliding dislocations (at most 10). But this small pile up may be enough to produce accommodation $\{10 \overline{1} 2\}$ twinning, because this twinning can be produced easily by small shear stress of the order of 200 to $300 \mathrm{~g} / \mathrm{mm}^{2}$ when magnesium crystals are extended nearly parallel to the c-axis ${ }^{(8)}$.

This process may be the Photo. 3 type kink formation mechanism. Once these kink bands are locked with the accommodation twins, they may become strong obstacles to gliding dislocations. Then the number of dislocations in the pile up may more and more increase during further deformation, resulting in lattice bending, further kink bands formation and accommodation twinnings. against the kinked portion. These twins occurred on both sides of the kinking. Burke and Hibbard ${ }^{(9)}$ also observed $\{11 \overline{2} 0\}$ kinking with many $\{10 \overline{1} 2\}$ twins in magnesium single crystals, in the vicinity of the gripped portions of the specimens. The accommodation twins observed by them occurred only on the tension side of kinking in many cases. Those twins were produced probably by another cause than that for the A region type twins shown in Fig. 3. They were produced probably by the bending stress yielded from the macroscopic bending of the specimen near the gripped portion, as reported by Burke and Hibbard. This type of twins produced probably by the bending stress were also observed in the present experiment in the middle part of the specimen as well as in the part near the gripped portion, as seen in the B region of Fig.3 and Photo. 3 . They are larger in size than those in the $A$ region and can be seen only on the lower side of the kinking, that is the tension side. In this orientation, all $\{10 \overline{1} 2\}$ twinnings produce an extension of the specimen. This means that twinning occurs preferably in some portion where the tensile stress is large. This may be the reason why the bend accommodation twinning in this crystal of large $\chi_{b}$ occurred preferably on the tension

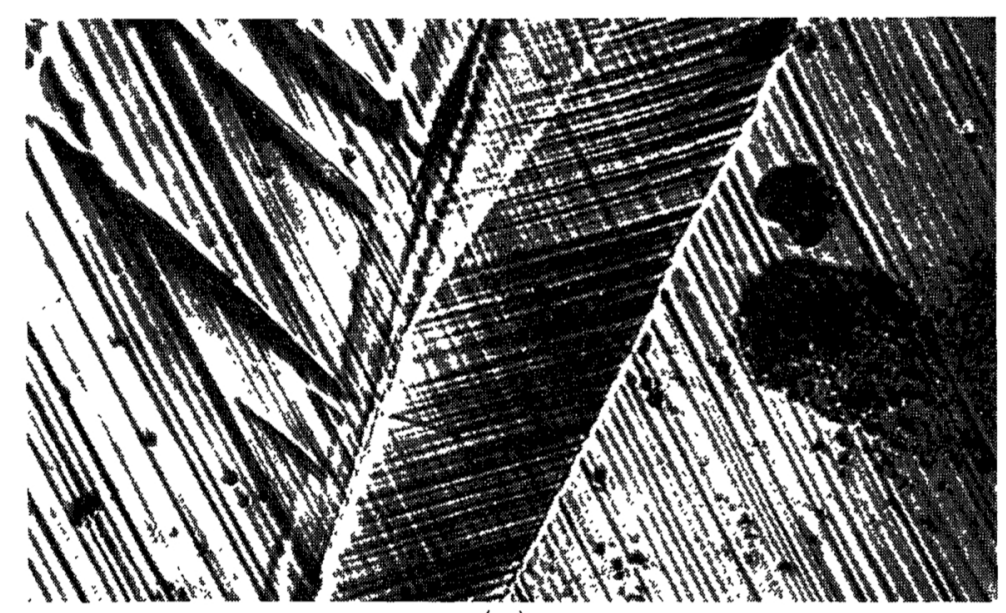

(a)

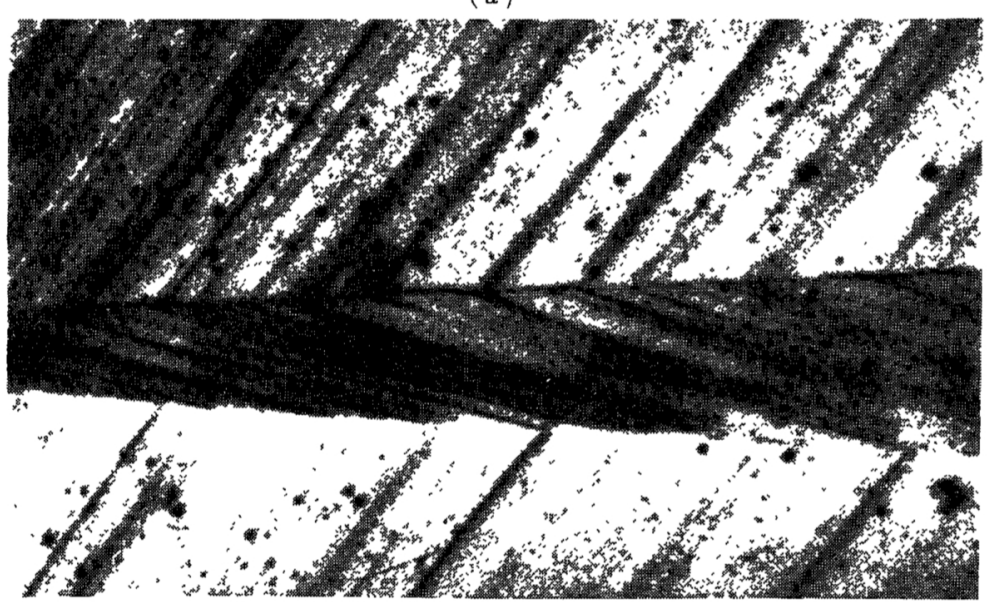

(b)

Photo. 6 (a) Many basal slip traces running through the twinned region. However, this merely shows that twins occurred after the formation of these slip traces.

(b) Both basal slip lines in parent cryrtal and in a twinned region end on the twin boundary.

Many fine twins are seen along the kinking in the A region of Fig. 3 and Photo. 3. They are considered to be accommodation twins of the piled up dislocations side of kinking.

In short, the weak barrier composed of parallel dislocations of opposite signs may be formed first, then 
small dislocation pile up occurs against this barrier, and produces accommodation twins of the $A$ region type.

Large dislocation pile up occurs against this barrier locked with the accommodation twins, and it causes lattice bending, resulting in heavy macroscopic bending of specimen. Then, large angle kinking and the accommodation twins of the $B$ region type may be produced to accommodate this macroscopic bending of the specimen.

The composition planes of $\{10 \overline{1} 2\}$ twinning intersect the basal plane in the parent crystal along the line parallel to the $\langle 11 \overline{2} 0\rangle$ direction. In the cases of

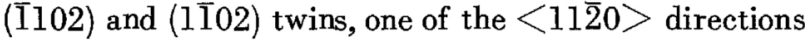
in the reoriented twin region is parallel to the active slip direction, [11 20$]$, of basal slip in the parent crystal. Accordingly, glide screw dislocations on the basal plane in the parent crystal are considered to be able to cross glide onto the reoriented basal planes in these twinned regions. However, in the other four kinds of $\{10 \overline{1} 2\}$ twins, all of the $\langle 11 \overline{2} 0\rangle$ directions are not parallel to the active slip direction of the basal slip in the parent crystal. Accordingly, the twin boundaries of these four kinds of twins may be strong barriers for the basal slip in the parent crystal.

Therefore, these accommodation twins as well as locked kink bands may contribute to work hardening, although (1102) and (1) 102$)$ twins may not be so strong a barrier as the other four kinds of $\{10 \overline{1} 2\}$ twins.

Basal slip bands across twin boundaries were often observed, as shown in Photo. 6 (a). However, this observation dose not show that the basal slip in the parent crystal can run through the twinned region across the twin boundary, but merely shows that these twins occurred after the formation of the basal slip bands, because the slip bands across the twin boundary were never observed in the case where slip deformation occurred after twin formation (Photo. $6(\mathrm{~b})$ ). This may show that the twin boundary is a strong barrier for basal slip.

Thus the segmenting process in single crystals mentioned above may be the work hardening mechanism of stage II of magnesium basal slip.

As the temperature increases, glide dislocations more easily avercome the obstacle composed of the parallel dislocations of opposite signs by the climbing motion, and more easily cross glide to a non-basal plane ${ }^{(19)}$, and further thermal recovery occurs much more rapidly. Accordingly the work hardening rate in stage I becomes less and its plastic region becomes wider as shown : in Table 1 . This means that the dislocation pile up becomes less and Photo. 3 type kink bands occur less frequently. Thus stage II of magnesium basal slip deçreases as the temperature increases. This hardening mechanism of stage II may illustrate also the lack of stage III in the work hardening curve of magnesium bąsal slip.

\section{Acknowledgment}

The authors are thankful to Professor H. Asada of the Aeronautical Research Institute, University of Tokyo for his hearty encouragement.

(19) P. W. Flynn, J. Mote and J. E. Dorn: Trans. AIME, 221 (1961), 1148. 